\title{
Impact Diamonds: Types, Properties and Uses
}

\author{
V. Afanasiev ${ }^{1(凶)}$, N. Pokhilenko ${ }^{1}$, A. Eliseev ${ }^{1}$, S. Gromilov ${ }^{2}$, \\ S. Ugapieva ${ }^{3}$, and V. Senyut ${ }^{4}$ \\ 1 VS Sobolev Institute of Geology and Mineralogy, Siberian Branch, \\ Russian Academy of Sciences, Novosibirsk, Russia \\ avp-diamond@mail.ru \\ 2 Nikolaev Institute of Inorganic Chemistry, Siberian Branch, \\ Russian Academy of Sciences, Novosibirsk, Russia \\ ${ }^{3}$ Diamond and Precious Metal Geology Institute, Siberian Branch, \\ Russian Academy of Sciences, Yakutsk, (Sakha) Yakutia, Russia \\ ${ }^{4}$ Joint Institute of Mechanical Engineering of the NAS of Belarus, \\ Minsk, Belarus
}

\begin{abstract}
Popigai is the world largest crater produced by an impact event. Abundant graphite in the target rocks underwent martensitic transformation into a mixture of high-pressure phases (an aggregate of nanometer cubic diamond and hexagonal lonsdaleite crystals), and some amount of graphite survived as a residual phase. They are of two types: (i) diamonds extracted from tagamites as chips of grains crushed during processing; (ii) yakutites in placers inside and around the crater, which formed at the impact epicenter and dispersed during the event. The impact diamonds possess exceptional abrasive strength, 1.8 to 2.4 times greater than in synthetic diamonds. The outstanding wear resistance, a large specific surface area and a thermal stability $\left(200-250{ }^{\circ} \mathrm{C}\right.$ greater than in synthetic diamonds) are favorable for main technological uses. With these properties, impact diamonds are valuable as material for composites and tools.
\end{abstract}

Keywords: Impact crater $\cdot$ Impact diamond $\cdot$ Yakutite $\cdot$ Abrasion strength

\section{Introduction}

The Popigai impact crater located in Yakutia (Russia) stores unlimited amounts of impact diamond with exceptional technological properties.

Studies of the Popigai impact crater have a dramatic history. The research was active from 1971, when V.L. Masaitis first proved the impact origin of the crater, to 1986, when the work stopped unexpectedly. Since neither geological surveys, nor engineering testing were undertaken; the testing was impossible because few diamond samples were available. In 2010 we got a collection of impact diamonds (about 3000 carat) from previous work at Popigai and resumed the tests. In this paper we characterized the diamonds as valuable raw for advanced technologies. 


\section{Popigai Impact Diamonds}

A huge crater, about $100 \mathrm{~km}$ in diameter, formed $35.7 \mathrm{Ma}$ when a large bolid hit the Earth at the Anabar shield in Siberia (Masaitis et al. 1998). The target Archean gneisses of the Khapchan Group containing abundant crystalline graphite were broken, remolten and partly dispersed outside the crater. Thereby the graphite underwent martensitic transformation into a mixture of high-pressure cubic diamond and hexagonal lonsdaleite; some amount of graphite survived as a residual phase either in aggregates with high-pressure phases or as separate particles. Upon conversion, the graphite reduced in volume by 1.6 and the resulting diamond formed as aggregate of $\mathrm{n} * 10-\mathrm{n} * 100 \mathrm{~nm}$ crystals (Walter et al. 1992). Impact diamonds possess exceptional abrasive strength, greater than synthetic diamonds by 1.8 to 2.4 depending on relative percentages of phases. The ultrahard impact diamonds can be successfully used for composites and tools.

\section{Types of Impact Diamonds}

The Popigai diamonds comprise yakutites in placers and diamonds hosted by tagamites, the primary impact rocks.

Yakutites formed at the impact epicenter and dispersed during the event. Currently they are found in placers inside and around the crater. The farthest dispersed findings of yakutites occur $550 \mathrm{~km}$ away from the crater or even more. The yakutite aggregates of nanometer grains are $0.7-0.8 \mathrm{~mm}$ to $1.0 \mathrm{~mm}$ in size and have a shapeless morphology or sometimes preserve hexagonal contours of primary graphite. They formed at the highest pressure and consist of cubic diamond and hexagonal lonsdaleite. The presence of graphite appears in Raman spectra but is undetectable by X-ray diffractometry, possibly, because of minor contents.

Tagamite-hosted diamonds are extracted by crushing from very hard host rocks and thus have angular shapes and particle sizes from a few microns to $1 \mathrm{~mm}$. During subsequent flotation, large amounts of fine graphite are extracted along with diamond. These diamonds are likewise aggregates of nanometer diamond, lonsdaleite and graphite grains. Diamond chips look laminated like the precursor graphite. Impact diamonds from tagamite are of two species. A-diamonds are colorless or yellowish, almost fully consisting of the cubic phase; they are the most resistant to wear. Those of B species comprise cubic diamond, lonsdaleite and graphite and are slightly less resistant. Most of impact diamonds, including those we analyzed, are from the Skalnoye deposit in the southwestern flank of the Popigai crater, away from the epicenter. They formed by shock waves while the target rocks were melting and remained enclosed in tagamite, i.e. they originated at lower pressures than yakutites.

Thus, placer yakutites and tagamite-hosted diamonds share the same impact origin but formed at different pressures and evolved in different ways afterwards. The highestpressure yakutites were dispersed and quenched, and preserved their primary structure, whereas diamonds in tagamites underwent prolonged annealing in tagamite melt. The annealing explains the presence of nitrogen impurity (N3V) which lacks in yakutites. 
We explored the Udarnoye and Skalnoye sites within the Popigai crater. The Skalnoye deposit stores up to 100 carat diamond per ton of tagamite, while the total estimated resources exceed 162 billion carat (Masaitis et al. 1998). The resources in the whole crater are actually inexhaustible. The amount of yakutites in placers around the crater may reach 1.5 billion carat (Masaitis et al. 1998).

\section{Possible Uses of Impact Diamonds}

Possible uses of impact diamonds are based on their exceptional wear resistance. Only tagamite-hosted diamonds were studied. Micropowders were made from a collection of impact diamonds (mixed A and B species) at the Institute of Superhard Materials (Kyiv, Ukraine). The impact diamond micropowder of any grain size shows greater abrasive strength than synthetic diamonds (Table 1).

Table 1. Comparative abrasive strength of impact synthetic diamonds

\begin{tabular}{l|l|l|l}
\hline \multicolumn{2}{l|}{ Impact diamond micropowders } & \multicolumn{2}{|l}{ Synthetic diamond micropowders } \\
\hline Grain size, $\mu \mathrm{m}$ & $\begin{array}{l}\text { Abrasive strength, } \\
\text { relative units }\end{array}$ & Grain size, $\mu \mathrm{m}$ & $\begin{array}{l}\text { Abrasive strength, } \\
\text { relative units }\end{array}$ \\
\hline+60 & 5,05 & +60 & 3,67 \\
\hline $60 / 28$ & 6,53 & $60 / 28$ & 3,69 \\
\hline $40 / 20$ & 5,89 & $40 / 20$ & 3,54 \\
\hline $28 / 14$ & 5,70 & $28 / 14$ & 3,33 \\
\hline $14 / 7$ & 4,85 & $14 / 7$ & 2,91 \\
\hline $10 / 5$ & 3,80 & $10 / 5$ & 2,16 \\
\hline $7 / 3$ & 2,98 & $7 / 3$ & 1,71 \\
\hline $5 / 2$ & 2,20 & $5 / 2$ & 1,21 \\
\hline
\end{tabular}

The extremely hard impact diamonds can be superior substitutes for synthetic diamonds in industry. Furthermore, a large specific surface area and relatively high adsorption and thermal stability $200-250{ }^{\circ} \mathrm{C}$ greater than in synthetic diamonds, make impact diamonds excellent raw for composites. Sintered composites of "impact diamond - Fe-Ti bond" powdered in a planetary mill to 5 to $50 \mu \mathrm{m}$ granules show better polishing properties compared with similar powders based on synthetic diamond DSM 20/14 (Table 2).

Table 2. Comparative polishing properties of impact diamonds - Fe-Ti bond and similar powder of synthetic diamonds

\begin{tabular}{|c|c|c|c|c|}
\hline \multicolumn{2}{|l|}{ Composite powders } & Polished material & Weight loss (mg/min) & Stability (min) \\
\hline Fe-Ti/impact diamond & $5 / 50$ & Silica & 35,4 & $>30$ \\
\hline $\mathrm{Fe}-\mathrm{Ti} / \mathrm{ACM}$ & $5 / 50$ & Silica & 17,8 & 14 \\
\hline
\end{tabular}


The impact diamond-based abrasive powders used for magnetic-abrasive polishing of silica plates have 1.5-2 times greater strength and 2 times greater stability (lifetime) than their counterparts made from synthetic diamonds (Table 2).

The technological properties of yakutites remain poorly investigated. They obviously have a very high wear resistance, possibly, higher than in tagamitic diamonds, while their grain sizes are suitable for using them in blade tools.

Meanwhile, apart from abrasive properties, there is a large scope of potential uses associated with structure, phase composition, etc. Currently, the only problem is the shortage of diamond specimens for testing. Sufficient amounts of such specimens can be obtained by building a pilot plant for extraction of diamonds.

\section{Conclusions}

The Popigai impact diamonds possess exceptional abrasion strength, large specific surface area and high thermal stability superior over the respective properties in synthetic diamonds. With these technological properties and actually unlimited resources, the impact diamonds are valuable industrial raw. The development of the Popigai diamond deposit can be successful due to progress.

Acknowledgements. The work was supported by grants 16-05-00873a and 17-17-01154a of the Russian Foundation for Basic Researchers and was carried out as a part of the Project No. 03302016-0006.

\section{References}

Masaitis VL, Mashchak MS, Raikhlin AI, Selivanovskaya TV, Shafranovskiy GI (eds) (1998) Diamond-bearing impactites from the popigai impact crater. VSEGEI, St. Petersburg

Walter AA, Eryomenko GK, Kvasnitsa VN, Polkanov Y (1992) Carbon minerals produced by impact metamorphism. Naukova Dumka, Kiev

Open Access This chapter is licensed under the terms of the Creative Commons Attribution 4.0 International License (http://creativecommons.org/licenses/by/4.0/), which permits use, sharing, adaptation, distribution and reproduction in any medium or format, as long as you give appropriate credit to the original author(s) and the source, provide a link to the Creative Commons license and indicate if changes were made.

The images or other third party material in this chapter are included in the chapter's Creative Commons license, unless indicated otherwise in a credit line to the material. If material is not included in the chapter's Creative Commons license and your intended use is not permitted by statutory regulation or exceeds the permitted use, you will need to obtain permission directly from the copyright holder.

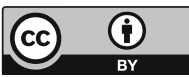

